\title{
A QUANTITATIVE APPROACH FOR SUSTAINABLE URBAN WATER MANAGEMENT SUPPORT
}

\begin{abstract}
Water resources play multiple urban roles. Available literature shows that the roles are mainly perceived in economic and technological context of fresh water delivery, sewage management and treatment as well as rain water runoff management. Water may play, nevertheless, other roles that are important for sustainable urban development. This is especially true in the case of habitats where both surface water and rain water serve as important component of urban space that brings multi-dimensional merits. Management of water resources influences surrounding environment in a multi-dimensional manner and has a considerable effect on ultimate quality of urban environment. Some proposals for the systemic assessment of water resource management in urban sustainable development context are available in literature. The application of multi-dimensional intangibility-aware analysis is recommended in this regard. However, existing studies lack an indication of concrete tools for supporting such analysis. This is why an AHP/ANP-based implementation of a selected framework for water management influence on urban space quality is discussed in the paper.
\end{abstract}

Keywords: surface water, rain water, management, influence, urban space, quality, assessment, AHP/ANP.

\section{Introduction}

Appropriate management of available resources facilitates reviving urban planning and management. However, successful development of public urban space requires thinking about possible solutions for solving appearing urban problems by means of a holistic view application. Such view facilitates the consideration of very diverse only social, cultural, aesthetic, economic, and environmental issues. Moreover, possible interrelations between these issues should be also taken into account.

Urban water system is not an exception with this regard. It is obvious that water is a necessary resource for a man to live. Other important functions of urban water resources deal with a distributed water retention, irrigation, and fire fighting. The resources are also capable of providing numerous means to revive urban space too. However, effects of International Symposium on the Analytic Hierarchy Process 
managing water resources for such purpose depend on the establishment of a reasonable compromise between needs for providing necessary means for ecological, hydrological, spatial, technical, economical, societal and cultural functions of urban water resources and a need for a sustainable urban space development. A disciplined integrated approach is thus required to manage urban water resources to attain at such compromise.

There are different measures available to fulfill different needs related to urban water management. Numerous and diverse factors should be also dealt with in this regard. A reliable and robust evaluation of available measures is thus required to arrive at a reliable compromise between different dimensions of urban water resource management. This why a proposal of a quantitative approach for urban water management support is presented in the paper.

\section{Literature Review}

Literature pertaining to urban water management usually concentrates on peculiar issues of water supply, sewage collection and treatment as well as flood control. Technical and economical dimensions are mainly taken into the consideration with this regard.

Only recently a number of papers dealt with a welcome systemic water management in sustainable urban development context. For example, Barron et al. (2017) discuss a need for an interdisciplinary research in urban water management for sustainable city development, Cameron and Katzschner (2017) suggest the tight integration in planning for urban development and planning of water systems, Wang et al. (2017) propose to integrate landscape components into urban water environment governance for sustainability-oriented comprehensive ecological control of urban water system. Possible intangible merits resulting from the application of urban water entities are also acknowledged (Wang et al., 2016).

There are several frameworks available in literature that allow and facilitate the assessment of the influence of water on quality of urban space in sustainable city development context. However, they are usually based not only on the application of quantitative data but also on descriptive opinions provided by experts. This is why the results of their direct application may suffer from negative influence of the subjectivity of provided information. Solely descriptive nature of utilized information also impedes its reliable processing and aggregation.

An evaluation frameworks for urban water entities are presented by (Januchta-Szostak, 2011). It is finally utilized for the implementation of a quantitative evaluation framework which is discussed in the following section.

International Symposium on the Analytic Hierarchy Process 


\section{Multi-criteria assessment system implementation}

The approach presented by Januchta-Szostak (2011) is Water Impact on the Quality of Urban Space (WIQUS). It constitutes an assessment system for the evaluation of effects of the management of urban surface and rainwater on urban space quality. It may be applied both as a design support tool and as general decision support tool. It provides necessary means for the comparison of different specific goals and hindering possible subjectivity while assessing possible spatial, societal, ecological, hydrological and economic benefits.

The approach makes use of information about nature and scale of assessed urban water entity as well as information about nature of surrounding environment, problem areas, threads and needs. A sequence of three distinct stages is applied in this regard:

1. State analysis and diagnosis of considered urban water entities and surrounding environment.

2. Analysis of the entities.

3. Multi-criteria assessment of the entities.

The last stage provides aggregated information about synergistic effects that result from diverse benefits brought by the application of individual options. Considered benefits pertain to four dimensions of relations between urban water entity and urban space:

1. Spatial dimension that deals with:

- aesthetic, coherence, and compositional merits,

- cultural values.

2. Societal dimension that deals with functional merits:

- accessibility and usage comfort,

- educational merits and integrating merits,

- attractiveness including recreational merits.

3. Ecological and hydrological dimension that deals with the following merits:

- natural environment quality,

- climatic comfort,

- water resources.

4. Economic dimension that deals with the following merits:

- economic value,

- maintenance cost,

- technical infrastructure efficiency.

Note that the dimensions deal with diverse areas and a number of diverse issues appears in the case of each dimensions. For example, increase in value of adjacent real estates, greened area attractiveness, work places and accommodation as well as in number level and diversity of available services may be considered in the case of economic value. Specialized knowledge is required, therefore, to provide a solid basis for reliable

International Symposium on the Analytic Hierarchy Process 
assessment of available options. The engagement of specific experts is thus required to utilize the approach.

It is evident that the dimensions and their constituents are capable of providing reliable means for the assessment of any urban water entities and their components. They are capable, therefore, of playing role of assessment criteria. One should be also aware of the fact that WIQUS doesn't make any assumption about kind of relations between them. Nature of the approach makes it well suited, therefore, for AHP/ANP-based quantitative implementation.

\section{Conclusions}

Water plays important and multidimensional role in city management and development. This is why urban water management deals with multi-disciplinary problems. Reliable assessment of merits provided by urban water is necessary, therefore, to provide appropriate solutions for urban water management problems.

Available literature presents numerous studies on the assessment of urban water entities and their components that aim at effective urban water management. The studies describe of possible approaches which deal with numerous intangible issues. Application of intangible issues make them hard to implement in a way that would limit the influence of subjectivity while trying to obtain reliable assessments. However, the application of appropriate tools makes it finally possible. This is why the proposed implementation of a selected assessment approach is based on one of such tools, namely AHP/ANP.

Software implementation of selected approaches is intended to be developed soon to facilitate reliable assessment of urban water spaces by interested parties, namely urbanologists, city development planners, city officials etc. Even standard AHP/ANP measures, including multiple experts participation, are helpful in this regard. One should nevertheless note that AHP/ANP provide additional merits e.g. Benefits-OpportunitiesCosts-Risks (BOCR) analysis, sensitivity analysis or diverse assessment scales. The merits might also prove to be interesting means for, practically unlimited, future development of software implementation. However, decisions about their utilization would result from discussion and actual needs of possible software users.

\section{Key References}

Barron, N.J., Kuller, M., Yasmin, T., Castonguay, A.C., Copa, V., Duncan-Horner, E., Gimelli, F.M., Jamali, B., Nielsen, J.S., Ng, K., Novalia, W., Shen, P.F., Conn, R.J., Brown, R.R., \& Deletic, A. (2017). Towards water sensitive cities in Asia: An interdisciplinary journey. Water Science and Technology 76(5), 1150-1157.

International Symposium on the Analytic Hierarchy Process 
G. Ginda, D. Dawiec: A QUANTITATIVE APPROACH FOR SUSTAINABLE URBAN WATER MANAGEMENT SUPPORT.

Cameron, R., \& Katzschner, T. (2017). Every last drop: the role of spatial planning in enhancing integrated urban water management in the City of Cape Town. South African Geographical Journal 99(2), 196-216.

Wang, J., Qin, \& Y., Zhang, C. (2017). Comprehensive ecological control of urban water system based on sustainability. Boletin Tecnico/Technical Bulletin, 55 (10):693-700.

Januchta-Szostak, A. (2011), Water in a townscape. Poznań University of Technology, Poznań 2011.

\section{ACKNOWLEDGEMENTS}

Publication of the article was financed by the AGH University of Science and Technology, Cracow, Poland (subject subsidy for maintaining research potential).

International Symposium on the Analytic Hierarchy Process 